\title{
Representaciones discursivas juveniles en prácticas escolares de escritura ${ }^{1}$ Juvenile discursive representations in school writing practices
}

Recibido: 08 de agosto de 2015 - Revisado: 03 de abril de 2016 - Aceptado: 30 de junio de 2016.

Gabriela Palazzo ${ }^{2}$

Roberta Marchese ${ }^{2}$

\section{Resumen}

Los estudios sobre juventudes han crecido sustancialmente en el marco de contribuciones inter y transdisciplinarias. En este contexto, los estudios del discurso cobran especial importancia como campo de análisis de las formas de representación de la juventud, entendiendo que el discurso es una práctica social. Este artículo examina qué representaciones discursivas sobre juventud emergen de producciones escritas de estudiantes de una institución educativa privada de Tucumán, Argentina. Se pretende visibilizar las problemáticas y temas juveniles desde los sujetos sociales que se estudian.

\section{Palabras clave}

Representaciones discursivas, juventud, escritura, ámbito escolar.

\begin{abstract}
Studies on youth have grown substantially within the framework of inter- and transdisciplinary contributions. In this context, discourse studies are especially important as a field of analysis of the forms of representation of youth, since discourse is a social practice. This article examines which discursive representations about youth are emerging from written productions by students from a private educational institution in Tucumán, Argentina. It aims to make visible the youth problems and issues from the social subjects that are studied.
\end{abstract}

\section{Keywords}

Discursive representations, youth, writing, school field.

\footnotetext{
1 Artículo resultado de investigación elaborado en el marco del proyecto "Prácticas discursivas en diversos contextos presentes y pasados: ELE, ciberespacio, medios de comunicación y otros", del Consejo de Investigaciones de la Universidad Nacional de Tucumán (CIUNT) y el CONICET.

${ }^{2}$ Doctora y docente en Letras de la Universidad Nacional de Tucumán, Argentina. Investigadora asistente del CONICET. Miembro del Instituto de Investigaciones Lingüísticas y Literarias Hispanoamericanas (INSIL) y del Instituto de Investigaciones sobre el lenguaje y la Cultura (INVELEC) Correo electrónico:

gabupalazzo@gmail.com

${ }^{3}$ Licenciada en Letras de la Universidad Nacional de Tucumán. Miembro del Instituto de Investigaciones Lingüísticas y Literarias Hispanoamericanas (INSIL). Estudiante de Maestría en Psicología Social de la Universidad Nacional de Tucumán y

Docente de escuelas secundarias.

Correo electrónico:

robertaimarchese@gmail.com

Para citar este artículo use: Palazzo, G., \& Marchese, R. (2016). Representaciones discursivas juveniles en prácticas escolares de escritura. Civilizar Ciencias Sociales y Humanas, 16(31), 219-234.
} 


\section{Planteamiento de la problemática de estudio}

El presente artículo tiene como objetivo indagar por cuáles son las creencias, mandatos, ideologías y variables que estructuran o bien dan sentido a la construcción y representación discursiva de los y las jóvenes a partir de sus prácticas de escritura en una experiencia de aula. Comprender al discurso como parte de las prácticas sociales, es el punto de partida que planteamos para encarar el estudio de escrituras juveniles e indagar en aquellas representaciones que puedan conformar los modelos mentales o de pensamiento.

Para tal fin, la exposición girará en torno a las siguientes cuestiones: a) la problemática de estudio; b) la metodología de trabajo: donde nos referiremos a las motivaciones y características de la experiencia sobre un proceso de visibilización de los jóvenes en sus discursos; c) el marco conceptual de referencia, d) los resultados: categorías emergentes de representación discursiva y e) las conclusiones.

El trabajo se incluye en una línea general de investigación sobre representaciones sociales, categorizaciones y definiciones de la juventud en los diferentes discursos sociales y a través de prácticas comunicativas diversas en Argentina. Se emplean métodos propios del análisis del discurso y el análisis crítico del discurso, considerados como interdisciplinas que dialogan con la sociología, la psicología social, los estudios de juventudes y la antropología, entre otras.

En los últimos años se ha reforzado la voluntad de investigar a los jóvenes y sus diferentes formas de existencia, atendiendo tanto a las construcciones sociales que los definen e imaginan desde un lugar institucional o adultocéntrico, como a las propias expresiones juveniles en distintos escenarios.

Este estudio surge de una experiencia de aula de la asignatura "Proyecto de investigación e intervención sociocomunitaria" que se dio a lo largo del ciclo lectivo 2013 con alumnos del último año del secundario, de la modalidad de humanidades y ciencias sociales. Los estudiantes que participaron tenían entre $17 \mathrm{y}$ 18 años al momento de aplicar la experiencia. La institución donde se llevó a cabo la investigación es un colegio de gestión privada, confesional católico (aunque se aceptan alumnos practicantes de otras religiones) y con casi cincuenta años de trayectoria en el ámbito educativo.

Se encuentra en la zona norte de San Miguel de Tucumán, capital de la provincia de Tucumán, que se ubica en la región noroeste de la Argentina. Se trata de un área residencial, de alta densidad demográfica, cuyos habitantes se consideran de un poder adquisitivo medio y alto. Los estudiantes, en una gran mayoría, pertenecen a familias de clase media, profesional y no profesional. El corpus de referencia en este trabajo corresponde a 34 textos escritos individualmente.

\section{Acerca de la asignatura. Construc- ción y evolución.}

Esta experiencia de aula, de la que surgieron las escrituras que analizamos aquí, resulta significativa dentro del contexto de la asignatura donde se gestó. Por esto, consideramos relevante realizar un recorrido de evolución de la materia "Proyecto de investigación e intervención sociocomunitaria" para dimensionar sus implicaciones en las realidades juveniles actuales.

La asignatura constituye un espacio curricular relativamente nuevo en la institución escolar donde se ejecutó este trabajo de campo. Desde sus inicios, los objetivos que se plantearon fueron indagar en realidades sociales significativas a partir de conceptos y marcos teóricos; promover el desarrollo de las capacidades de los alumnos para la generación de transformaciones concretas; y fomentar la mi- 
rada crítica, la reflexión, el diálogo y el debate permanentes.

Tres años antes de esta experiencia, cuando se presentó por primera vez la materia y la propuesta de un proyecto tanto de investigación como de intervención, se observó que los alumnos relacionaban el intervenir en la comunidad con el puro asistencialismo. Esto es, planteaban acciones despojadas de un diagnóstico previo, de un marco teórico, de objetivos, de fundamentación y de un propósito que apuntara a una verdadera transformación.

Asimismo, llamó la atención que los jóvenes elegían temas para investigar y diseñaban modos de intervención que no manifestaban un interés real de su parte. A su vez, consideraban que, en oposición a los proyectos que se desarrollaban en la modalidad de economía y gestión -otra de las orientaciones que ofrece el colegio en el secundario-, ellos no tendrían ningún producto - un producto material, para crear, inventariar, publicitar y comercializarque fuera el resultado evidente del trabajo de todo un año.

Más adelante se evidenció que existe una suerte de temas de investigación predilectos y frecuentes en las instituciones escolares (la trata de personas, las adicciones, el bullying, la violencia de género, el aborto), que son requeridos desde las mismas consignas: la monografía, la investigación y la clase expositiva entre pares. También se advirtió que estos formatos discursivos, de estructura canónica -y canonizada por la institución escolar-, no admitían variaciones e innovaciones significativas.

Por otra parte, se notó que, pese a que la asignatura debía constituir un espacio de reflexión, debate, análisis y generación de ideas relacionadas con los intereses de los jóvenes, las temáticas que ellos consideraban relevantes o escolarmente investigables, poco tenían que ver con la juventud o se las abordaba desde una juventud ajena y extraña a la suya. Incluso atendían a realidades externas a la institución educativa donde asistían.

De este modo, el bullying se trabajaba como una problemática que se constreñía al dramatismo y efectismo de filmaciones en que un joven era golpeado por sus compañeros, o en que un adolescente realizaba una confesión, previa a su suicidio, por haber sido hostigado por su identidad sexual. El aborto se identificaba como propio de adolescentes en situación de vulnerabilidad social; las adicciones y la violencia de género quedaban relegadas a textos expositivos que desarrollaban sus síntomas y consecuencias (muchas veces acompañados de instructivos que detallaban cómo actuar en caso de conocer personas adictas $o$ víctimas de violencia); y la trata de personas, principalmente de jóvenes mujeres, se remitía a casos paradigmáticos de la Argentina.

Los trabajos terminaban consistiendo en un recorrido por lugares comunes (se reproducían sin cuestionamientos ni reflexión de la información de Internet, muchas veces de páginas poco fiables) y las acciones que se desarrollaban se limitaban a campañas de concientización para impedir el bullying, o evitar el aborto, ser víctima de la trata de personas, de las adicciones y de la violencia de género. Estas acciones se completaban con el empleo de imágenes de alto impacto relacionadas con las distintas problemáticas.

Si bien la elección de la temática era personal, la gran mayoría de las investigaciones y de los proyectos era ajena a sus propios intereses. Así mismo, se observó que los alumnos manifestaban dificultades para encontrar una postura, una opinión personal y que les generaba inseguridades usar su propia voz.

Por lo tanto, la autoría de la palabra 'pensamiento', noción que adoptamos de Requejo (2004), especialista en lingüística social, se diluía, aunque tampoco se estimulaba desde la institución. La investigadora define la autoría 
de la palabra pensamiento como "una conquista y derecho inalienable de cada ser humano que posibilita desarrollar y expresar en libertad, sin censuras, humillaciones ni imposiciones, aspectos de su propia identidad lingüística, cognoscitiva, afectiva, política y sociocultural" (p. 32). Así, la autoría de la palabra pensamiento

[...] constituye un proceso progresivo de aprendizaje vinculado con experiencias y relaciones humanas cambiantes y su toma de conciencia desde los primeros años contribuye al desarrollo no solo lingüístico sino subjetivo, cognoscitivo, sociocultural, y a un posicionamiento activo en relación [con] la vida misma, [con] las experiencias y aprendizajes individuales y sociales (p. 32).

Pese a que en la institución se construyen espacios pretendidamente dialógicos y polifónicos, muchas veces prevalece la palabra monologal. Como sostiene Requejo (2002), se trata de prácticas institucionales que al reiterarse, conducen al sujeto hacía la adopción -ventajosa o no, valorada o no- de determinadas identidades y patrones de conducta normativizados, progresivamente se internalizan e impactan subjetivamente, tanto en el docente como en el alumno, configurando así una matriz de aprendizaje-enseñanza y una relación sujeto-mundo de "adaptación pasiva a la realidad".

Se reportó durante ese tiempo una suerte de paradoja: la asignatura Proyecto -y la escuela en general- debía promover la autoría de la palabra pensamiento, incluso la proactividad de los sujetos para intervenir y transformar la realidad; sin embargo, la fuerte impronta de años de procesos sutiles de silenciamiento, ocultamiento y desatención hacia la propia autoría, generaba un espacio de "investigación" superficial, que no respondía a las verdaderas inquietudes de los estudiantes.

De esta manera, se comenzó a orientar el trabajo en el aula hacia un complejo proceso de hacer consciente, explicitar, des-ocultar imágenes, ideas y creencias que circulaban sobre los jóvenes. Y, desde la labor docente se asumió la necesidad de contribuir a que los estudiantes desnaturalizaran determinados discursos, cuestionaran ciertas imágenes, indagaran, analizaran e interpelaran la realidad.

\section{Metodología de trabajo}

La metodología para la estimulación de las producciones individuales, como una auténtica práctica juvenil en el aula, consistió en un trabajo intensivo que abarcó alrededor de seis meses. Para iniciar el proceso, se partió de las siguientes consignas, que debían discutirse en grupo, luego responderse por escrito y, finalmente, ser expuestas en forma oral y colectiva en un plenario: ¿Qué se dice acerca de los jóvenes? ¿Quiénes lo dicen y en qué ámbitos? ¿Con qué ideas se asocia a los jóvenes? ¿Qué "nombres" utilizan en el colegio para hacer referencia a ustedes? ¿Qué implica ser joven en Tucumán?

Los debates en el aula que se extendieron por varias semanas, fueron sumamente valiosos pues, con el paso de los días, las reflexiones se hacían cada vez más profundas. El docente guio y orientó las exposiciones de cada grupo, promovió el diálogo y la escucha activa, destacó ideas, señaló las recurrencias temáticas en las respuestas grupales y fomentó la reflexión en los estudiantes, con el propósito de que construyeran una postura personal, crítica y fundamentada acerca de la juventud.

En estos debates, se observó que en un primer momento los alumnos reproducían fragmentos de un discurso ajeno -adultocéntrico y mediático- sobre sí mismos, sin identificarlos como tales. Algunos estudiantes afirmaban la falta de compromiso y responsabilidad de los jóvenes, por ejemplo, mediante enunciados como "Somos hijos del rigor", "No sabemos aprovechar las oportunidades que nos dan nuestros padres o el colegio", "Es cierto que somos irresponsables". Otros, por el contrario, desde su lugar de enunciación, se recortaban de sus pares, de otros jó- 
venes, porque consideraban que se diferenciaban de estos al no tener los mismos intereses (salir a bailar, tomar alcohol, fumar, escuchar música comercial, etc.) y por saber, con convicción, qué querían para su vida futura (realizar estudios superiores, viajar, trabajar...).

Se leyeron artículos periodísticos de opinión y bibliografía especializada acerca de la juventud que sirvieron para profundizar y complejizar las discusiones. La metodología contempló, luego, la introducción de los conceptos de discurso y representaciones sociales, que permitió a los estudiantes reconocer en su discurso "lo propio" y "lo prestado y/o impuesto". Es decir, se abrió la posibilidad de identificar los lugares comunes en los que se incurre al hablar de los jóvenes ("juventud, divino tesoro" y "juventud perdida"), observar qué ideas están en la realidad, analizar imágenes que se usan para hablar de ellos con las que se sentían identificados o no, indagar en el concepto de juventud, investigar sobre jóvenes que se encuentran en una situación sociocultural de vulnerabilidad, diferente de la de ellos, entre otros aspectos.

A continuación, ya habiendo desmontado esas ideas fijas y preconceptos sobre los jóvenes, se propuso la elección de un tema de investigación relacionado con la juventud. Y la mayoría de los grupos (eran ocho) optó por temas novedosos, si se consideran los antecedentes de proyectos presentados en esta institución educativa. En estos trabajos el objeto de estudio fueron ellos mismos, sus compañeros de cursos menores y de otras instituciones, en relación con diferentes prácticas, asociadas frecuentemente a los jóvenes: la exposición en las redes sociales, el sexting, el bullying, representaciones de los chicos que se encuentran privados de su libertad, la participación y el sentido de pertenencia en el colegio, las prácticas habituales entre los jóvenes en un boliche de la capital de la provincia.

Los trabajos se socializaron entre los distintos grupos dentro de la clase y algunos se difundieron en otros cursos del colegio. El proyecto sobre participación escolar se presentó a los directivos con una propuesta de intervención sociocomunitaria novedosa y original en la institución: la realización de un campamento fuera de la ciudad como una manera de fomentar el protagonismo estudiantil, la autogestión, las actividades colaborativas y el sentido de pertenencia.

Pese a que estos alumnos egresaron al año siguiente, en 2014, con un nuevo grupo de estudiantes desde la asignatura se planificó volver sobre los temas planteados y desarrollados por sus antecesores. Así, los proyectos no concluyen con la finalización del ciclo lectivo, ni las acciones se agotan en un solo proyecto, sino que se completan, amplían, mejoran y replantean desde nuevas perspectivas, atendiendo a los cambios históricos y a las necesidades reales y sentidas de la propia comunidad. Esta instancia de concatenación de los proyectos grupales entre años sucesivos y de búsqueda conjunta de acciones y prácticas genuinamente juveniles, se reserva como una línea de continuidad para la presente investigación.

Por último, y en coherencia con la metodología aplicada, las escrituras personales se estimularon desde la consigna "Verdades y mentiras acerca de nosotros". De esta manera, las producciones fueron también el resultado de todo un trabajo previo, diseñado y planificado, que se aplicó sistemáticamente en el aula, con el objetivo de construir una base de conocimiento significativa para el proceso de investigar e intervenir en la realidad. En los siguientes apartados nos referiremos entonces, a la aproximación teórica que sustenta el análisis y a los resultados obtenidos.

\section{Marco conceptual}

El instrumento estudiado en esta experiencia está compuesto por enunciados que son prácticas discursivas, a las que se define como:

[...] la producción de discurso -en contexto histórico- por parte de sujetos para construir 
formas de representación del mundo, a partir de las representaciones sociales que organizan los esquemas de percepción y de apreciación con los cuales las personas clasifican, juzgan y actúan (Peralta, 2005, p. 11).

Estas forman parte de determinados ámbitos de prácticas sociales, ya que tienen naturaleza constructiva y representacional. Así mismo, y de acuerdo con Haidar (1992, p. 145), considerar a los discursos como prácticas supone darles dimensión fáctica, de acontecimiento, eliminando la separación analítica entre lo dicho y lo hecho. En tanto prácticas socioculturales, son hechos discursivos productivos $\mathrm{y}$ reproductivos.

Coincidimos con Raiter (2003) en que, al momento de comprensión/recepción o producción de un hecho de habla está presente un conjunto de discursos que conforma una red discursiva. Esta red impone un sistema de referencias y adopta la forma de representaciones.

En este trabajo pondremos atención en las representaciones discursivas, definidas como la construcción lingüística de creencias o imágenes sociales (Vasilachis de Gialdino, citado en Montecino-Soto, 2005) que pueden observarse, analizarse e interpretarse a partir de la ideología que albergan las prácticas sociales (Remedi, 2004). Aquí el discurso expresa y al mismo tiempo constituye las representaciones sociales (Pardo-Abril, 2003).

Un sistema de creencias es un mecanismo mental autónomo (Gardner, 1936, citado por Raiter, 2003, p. 77) por medio del cual las personas construyen representaciones e imágenes mentales y otros estímulos que les permiten orientarse en el mundo. Las características de este sistema de creencias son: a) interviene al momento de recibir un estímulo; b) un estímulo hace actuar de forma obligatoria al sistema; c) interpreta el estímulo y construye una representación mental de lo que ha escuchado o leído; d) es completo: contiene la información necesaria para producir algún tipo de representación ante un estímulo determinado; y e) tiene circuitos: actúa según una determinada organización y clasificación del contexto.

Raiter advierte que los contenidos de los sistemasdecreencias no semantienen constantes, pues los sucesivos estímulos van conformando nuevas imágenes o representaciones. Al respecto propone cuatro tipos de creencias ${ }^{1}$ : creencias $i$ : son individuales, sin posibilidad de convertirse en sociales; creencias $s$ : son las necesariamente sociales, necesariamente compartidas por los miembros de una comunidad; creencias $p$ : funcionan como referencia, los individuos y grupos sociales toman un valor acerca de ellas; $\mathrm{y}$ creencias ps: pueden ser sociales pero se comparten solo entre algunos grupos.

En el caso que estudiamos aquí, el tema propuesto por la docente "Verdades y mentiras sobre nosotros" es un estímulo orientado hacia las creencias $s$, en cuanto es innegable que los estudiantes forman parte de una comunidad que ha naturalizado ciertos rasgos como típicamente juveniles; a su vez, se espera que en la práctica discursiva estas imágenes operen como referencia para expresar una valoración (creencias $p$ ). Pero también, en algunos de los textos se advierten creencias $i$, que tienen que ver con el accionar o modo de actuar individual.

El contenido textual de los discursos no es transparente sino opaco, de allí la urgencia del análisis del discurso como instrumento de desvelamiento. En el caso del corpus seleccionado para este trabajo, se trata de textos escritos, orientados por un tema, por lo que es esperable que se estructuren en pos de enunciados valorativos. Quizá valga aclarar que, si bien estamos frente a contenidos y enunciados manifiestos, no expresarán necesariamente el contenido de experiencias reales de cada uno de los estudiantes, sino que más bien nos interesa la cristalización discursiva de ciertos sistemas de redes discursivas que intervienen en la definición social de juventud. 
Al respecto, corresponde identificar y analizar cómo opera en los textos del corpus el discurso dominante respecto de qué es ser joven o, más bien, qué creencias compartidas socialmente se valoran como válidas o no válidas en esa definición, a la luz del contexto al que se alude en los enunciados. De acuerdo con Raiter (2003) "Discurso dominante es un concepto abstracto, variable en el tiempo, definido como una red de referencias conformada por contenidos presentes en el sentido común que tiene la posibilidad de calificar todos los otros discursos posibles" (p. 71).

En cuanto al concepto de juventud, el discurso dominante ha variado de manera significativa a lo largo de la historia. Sincrónicamente, en el siglo XXI se comporta como un eje de referencias que reúne una serie compleja de representaciones, muchas veces contradictorias entre sí, pero que cristalizan en las prácticas discursivas cotidianas coloquiales e institucionalizadas.

Son muchas las categorías que ha construido el discurso académico respecto del concepto y definición de juventud, retomando discursos y representaciones desde la antigüedad clásica. En los textos que examinamos aquí, estas categorías de representación se alinean en un discurso donde "la" juventud como concepto imaginado y fijado en la memoria social se carga de rasgos valorativos positivos (ser el futuro, el cambio social, la posibilidad) y negativos (estar perdida, vivir solamente el presente, la irresponsabilidad, los vicios, etc.) $)^{2}$.

A partir de este eje de los discursos dominantes, los posicionamientos enunciativos de los estudiantes van categorizando las valoraciones, trasladando los lugares comunes del pensamiento social a su discurso. Esto ocurre en los segmentos donde prevalecen los actos de habla asertivos. Ejemplo (el énfasis es nuestro):

A los 17 años somos luchadores. Permanentemente estamos en una lucha de gustos, dis- gustos, aflicciones propias y de amigos. $\mathrm{Lu}$ chamos contra la presión que nos imponen los adultos. Que la universidad, que los estudios. [...] Esa es una lucha que los adultos no ven y sin intención alguna hacen nuestra lucha más dura. Ser joven significa ser luchador (Palazzo $\&$ Marchese, 09 de octubre de 2013, texto 2).

\section{Resultados}

\section{Regularidades discursivas predomi- nantes en las producciones escritas.}

Género discursivo: predomina el texto argumentativo de tipo ensayístico, si bien en una forma rudimentaria, pero que contiene los elementos básicos de la superestructura argumentativa. Así mismo, en otros géneros elegidos como el poema, el discurso argumentativo es el que da coherencia al enunciado.

En líneas generales, podemos elaborar algunas regularidades en los 34 textos según su forma típica como géneros discursivos (Bajtín, 1982), considerando la esfera de producción discursiva (instancia escolar):

- Función: predominio de función argumentativa/valorativa.

- Aspectos temáticos: la juventud, los jóvenes. Los discursos sobre los jóvenes.

- Composición o estructuración: ensayo, poema. Procedimiento de organización y progresión temática adecuados al género.

- Estilo: predomina el estilo formal en la selección de recursos lingüísticos, la variedad escrita.

- Expresividad típica (actitud valorativa del hablante hacia el enunciado ajeno): este aspecto es especialmente relevante porque vincula cada texto con la serie de representaciones sociales en los discursos dominantes vigentes, los convoca y reproduce o interpela a través de las siguientes modalizaciones 
asertivas: "es cierto que", "es difícil vivir con", "claro está", "esto no quiere decir que" y "no siempre es así".

Esta actitud expresa el rechazo a los modelos mentales cristalizados en el discurso social, sin desconocer sus visos de legitimidad en función de los habitus juveniles. Tal es el caso de la imagen prototípica de la juventud perdida por falta de estudios, por desinterés, pasatismo, hiperconectividad, etc. Por una parte, el discurso juvenil condena esa representación por generalizadora e injusta, pero por otra, admite que sí existen jóvenes no "normales". "Muchos jóvenes son así, no estudian y no se dan cuenta que algún día van a tener que trabajar para poder mantenerse o mantener a su propia familia" (Palazzo \& Marchese, 09 de octubre de 2013, texto 8$)$.

Posición enunciativa y subjetividad adolescente: el lugar de enunciación aunque es una instancia lingüística y abstracta, tiene correlación aquí con un lugar social de producción de sentido, que es el estrato sociocultural de los alumnos, su grado de escolarización y la pertenencia institucional. Ya en el discurso, se asumen posiciones como miembros de un grupo (los jóvenes del siglo XXI) y en relación con una generación. Si bien detrás o atravesando cualquier discurso hay un "yo" que toma la palabra y que será el que en definitiva imprime su ideología en el enunciado, en estos textos adopta otras formas gramaticales según se aleje afectivamente del objeto de su enunciado, para darle visos de impersonalidad, cercanía, etc. Ejemplos:

Yo: “desde mi punto de vista y por lo que estoy viviendo por estar en mi último año de secundaria..."(Palazzo \& Marchese, 09 de octubre de 2013, texto 6), "Yo considero que hay dos tipos de jóvenes..." (Palazzo \& Marchese, 09 de octubre de 2013, texto 8).

Nosotros: "hoy en día, nosotros los jóvenes ocupamos un rol importante para la sociedad" (Palazzo \& Marchese, 09 de octubre de 2013, texto 8), "Muchas veces hablan de los jóvenes, "nosotros' como si nada nos importara" (texto 12), "Somos jóvenes, nos equivocamos, no somos perfectos" (texto 13).

Impersonal: “...es muy difícil encontrar algo que los defina" (texto 25)

Mixtura entre ambas formas: “...dicen que los jóvenes están perdidos ya que están muy metidos en los vicios como ser alcohol, drogas, etc." (Palazzo \& Marchese, 09 de octubre de 2013, texto 12), "Para mí estos jóvenes están perdidos" (texto 12), "no todos los jóvenes están perdidos ya que es mentira, porque muchos de nosotros y creo que ninguno de mis compañeros consume droga o es un pibe chorro" (texto 12).

\section{Categorías emergentes en la repre- sentación discursiva de juventud.}

En cuanto a la referencia a ser joven, ya sea considerándose como parte de un colectivo o bien como tema del discurso ajeno, podemos establecer regularidades en la expresión de las subjetividades de este grupo de estudiantes, que reunimos en las siguientes categorías:

Generación: el discurso juvenil alude a la brecha de edad cronológica que los distingue de los padres y las instituciones: los adultos imponen mandatos sociales a los que los jóvenes deben responder, junto con expectativas de futuro, pero también imponen un discurso social. Esto se expone como una presión. Tal variable organiza construcciones discursivas como "según ellos, los jóvenes somos incapaces de hacer cosas que hacían ellos" o "cargamos expectativas que no son nuestras y con sueños frustrados".

En este sentido, cabe la reflexión de Urresti (1999) sobre qué define, finalmente, la condición de juventud. El sociólogo advierte que más que la estética o la moratoria social que 
se le atribuye a la adolescencia, tiene relevancia la experiencia generacional y la diferenciación con la generación precedente:

Tal vez el más importante de estos conflictos sea el generacional. Si hay algo que define el ser joven no es tanto una estética o una moratoria social $[\ldots]$ como el posicionamiento fáctico frente a las generaciones precedentes.

La juventud es esa facticidad que señala como un dato duro quiénes son precedentes y quiénes son posteriores. Y esto está más acá o más allá tanto de las estéticas que "definen" un grupo de edad, que en última instancia es un juego de apariencias sociales en disputa, como de las moratorias sociales desigualmente distribuidas en distintos sectores de la población.

[...] El crédito temporal disponible y la facticidad es lo que le da profundidad histórica a la experiencia personal en la que cada sujeto construye su propia identidad (pp. 21-22).

En referencia a la distancia simbólica o real que los separa de aquellos jóvenes que transitan experiencias vitales y prácticas diferentes a las de ellos, los estudiantes se imaginan desde un lugar de bienestar frente a la exclusión social de otros grupos juveniles.

Edad cronológica/biopsicológica: alusión a los 16 o 17 años y a la adolescencia. "A $\operatorname{los} 17$ años somos luchadores" (Palazzo \& Marchese, 09 de octubre de 2013, texto 2), "Hoy en día hay muchas jóvenes o adolescentes mujeres que están embarazadas o que tienen un hijo teniendo 15, 16 o 17 años" (Palazzo \& Marchese, 09 de octubre de 2013, texto 4).

Edad social ${ }^{3}$ : comportamientos sociales que distinguen a los jóvenes de otros grupos sociales en un mismo momento histórico. En nuestro corpus se representa como recortada, por deberes y obligaciones, de la niñez y la adultez. "Es difícil vivir con tantas pretensiones / ajenas a nuestras intenciones /ser niño... ser adulto... / ¡no se puede complacer a todo el mundo!" (Palazzo \& Marchese, 09 de octubre de 2013, texto 1).

[...] hay un grupo importante al que le importa lo que pasará en su futuro, al menos vive pensando en resolver cómo llegar con todas las materias aprobadas a fin de año o cómo colaborar un poco más en la casa (Palazzo \& Marchese, 09 de octubre de 2013, texto 26).

Territorio: el lugar geográfico de pertenencia si bien no se nombra como barrio o sector de la provincia, está implícito en las construcciones discursivas donde el sujeto de la enunciación se distingue, como joven, de otros jóvenes que habitan y se relacionan con sus pares en "zonas marginales" o "villas", e incluso "ambientes". En este punto, la representación individual del lugar social propio como joven se construye en la conjunción de territorio, identidad (o más bien, identificación) y clase social (Palazzo \& Marchese, 09 de octubre de 2013, textos 15 y 17).

[...] los medios de comunicación masiva difunden todo el tiempo información que nos hace ver mal. Pasan aquella parte de la población de jóvenes que solo roban, se drogan, fuman, es decir, aquellos que son vulnerables en la sociedad, de clase baja, y no aquellos que sí se interesan en la sociedad [...] (Palazzo \& Marchese, 09 de octubre de 2013, texto 15).

Por su parte, el texto 17 consigna:

[...] se refieren (los adultos) a esa parte marginada de la sociedad, aquellos (jóvenes) que andan sin rumbo en las calles, los que no priorizan la educación, sino el trabajo desde muy chicos, aquellos cuya situación es propensa a delinquir.

Podemos organizar entonces, dos formas de definición de juventud en relación con la representación social basada en la premisa "la juventud está perdida":

1. El "yo" que enuncia no se incluye en esa representación porque no está determinado por 
la pertenencia a un territorio de marginalidad o exclusión. "Para mí estos jóvenes están perdidos no solo por ser pobres, sino que son marginados por una sociedad que es diferente a ellos" (Palazzo \& Marchese, 09 de octubre de 2013, texto 12).

2. El "yo" que enuncia no se identifica con esa representación porque si bien reconoce los excesos y transgresiones sociales de los miembros de su clase o estrato social, evita incluirse como parte de ellos, o bien como sujeto capaz de racionalizarlos y advertir su peligrosidad. “También están los jóvenes como nosotros que para mí son todos aquellos que tienen una vida normal, salen de fiesta, toman pero en todo se controlan. Muchas veces se pueden pasar, pero siempre mantienen una línea formal" (Palazzo $\&$ Marchese, 09 de octubre de 2013, texto 21).

Tiempo: cobra significación el paso del tiempo en relación con la brecha generacional y tecnológica; la preocupación por el tiempo presente de existencia o bien el apremio por cumplir los mandatos sociales en un "tiempo" determinado (terminar los estudios, hacer una carrera universitaria en tiempo y forma, etc.). Es decir, el tiempo de la edad social que los recorta como jóvenes, y el de la moratoria vital que les pone un plazo para serlo. El futuro, el ser futuro también genera miedo.

“Tengo 17 años, sí, pero no hay tiempo que perder..." (Palazzo \& Marchese, 09 de octubre de 2013, texto 2). "La sociedad de hace veinte o treinta años no es la misma" (texto 19). "Los tiempos cambiaron y las cosas no son como antes" (texto 22). "Muchos se ocupan de sus vidas ordenadamente, estudian para ser 'alguien' en el mañana" (texto 23). "Estamos acá escuchando todo el tiempo a los adultos decir [...] 'te queda poco tiempo, apúrate!'” (texto 34 ).

Moratoria social: privilegio de las clases medias/altas.

También existen los "jóvenes peligrosos", como la gente los llama, que muchas veces salen a robar para poder llevar la comida a sus familias. [...] estos jóvenes hacen esto porque no tienen otras posibilidades y no conocieron ni tuvieron otras oportunidades para actuar de otra manera y tener una vida fuera de la droga, el alcohol, las peleas, los crímenes e incluso el trabajo desde que son niños (Palazzo \& Marchese, 09 de octubre de 2013, texto 25).

Y en el texto 14 se manifiesta:

En la clase más baja se presentan otras verdades, como por ejemplo: los que están en la calle, que no pueden acceder a un futuro mejor porque no tienen una educación $[. .$.$] no es$ justo para mí, estos jóvenes tendrían que estar estudiando para su propio bien y para que su futuro sea mejor (Palazzo \& Marchese, 09 de octubre de 2013).

Anomia social/descontrol: "es cierto que algunos reaccionan agresivamente cuando una persona los empuja sin querer porque no miden o no se controlan a sí mismos" (Palazzo \& Marchese, 09 de octubre de 2013, texto 10), "Somos muy rebeldes y no nos gusta que nos pongan un orden" (texto 18), "Puede ser que algunas de nuestras actitudes sean descontroladas..." (texto 28).

Etapa: de disfrute, de libertad, de rebeldía y equivocaciones. "[...] la juventud de hoy en día sale y toma para divertirse y pasar un buen tiempo disfrutando" (Palazzo \& Marchese, 09 de octubre de 2013, texto 10), "La juventud es una etapa justamente para eso, disfrutar antes de ser adultos y tener que ser responsables" (texto 7).

Lugar social: en estos enunciados se menciona su función relevante como sujetos sociales. "Hoy en día los jóvenes ocupamos un rol importante para la sociedad; debido a este motivo siempre hacen críticas, ya sean buenas o malas hacia nosotros" (Palazzo \& Marchese, 09 de octubre de 2013, texto 8), "Somos la promesa al mundo y estamos considerados como chicos del futuro, es por eso que los mayores nos juzgan tanto nuestros pasos y 
nuestras decisiones" (texto 16), "Los jóvenes son un segmento de población muy importante" (texto 26).

Son los adultos (en general), los padres y los medios masivos de comunicación los agentes explícitos que se citan como generadores de construcción de representaciones sociales sobre jóvenes. Es decir, se les atribuye la responsabilidad de nombrar a los jóvenes y, de este modo, limitar su representación a ciertas características socioculturales, de prácticas, habitus y modos de estar juntos, que resultan en imágenes negativas proyectadas a la sociedad en general.

\section{Creencias sociales de base para es- tructurar la argumentación.}

Los enunciados dialogan con las premisas que mencionaremos a continuación. Por lo general en forma explícita, pero en algunos casos implícitamente y se deducen de la totalidad del discurso. Se asume que es la sociedad la que reproduce estas imágenes y ellos deben cargar con ellas.

Por un lado, estas representaciones se esgrimen como parte de las cristalizaciones del discurso dominante en la cognición social. Pero por otro, se utilizan como argumento para la estrategia de afiliación o desafiliación de un grupo. Destacamos tres creencias sociales:

"La juventud está perdida": en este caso funciona como resorte discursivo la apropiación de los argumentos del texto de opinión de la ensayista y periodista argentina Beatriz Sarlo (2006), trabajado en clase: “¿Quién perdió a la juventud perdida?". Desde este lugar, los jóvenes son representados no ya como "perdidos" para la sociedad por su modo de existencia y sus prácticas o vicios, sino como sujetos vulnerables que han sido "perdidos" por la sociedad.

"La juventud es el futuro": es la proposición mediante la que se ubica a ciertos adolescentes o jóvenes dentro de un sector social interesado "por" su futuro, proyectándose en el estudio, el trabajo, etc. Así mismo, se registra la tercera creencia que es opuesta: "el futuro de la sociedad está perdido".

\section{Estrategias discursivas globales de representación.}

Tópicos discursivos: la carrera universitaria, el trabajo, el umbral entre secundaria y universidad, el embarazo adolescente, los planes sociales, etc. "El tema más frecuente de conversación es acerca de nuestra carrera universitaria" (Palazzo \& Marchese, 09 de octubre de 2013, texto 6), "Están los jóvenes estudiosos a los que les importa el futuro, muchos de ellos trabajan, les importa ser profesionales el día de mañana o tener su título" (texto 8), "Por lo menos en el último año se siente una gran presión de alcanzar "el objetivo deseado"" (texto 34), "Hay muchas chicas jóvenes que quedan embarazadas siendo jovencitas [...] y la mayoría quedan embarazadas por cobrar unos cuantos planes sociales" (texto 4 ).

Generalización: "Para la gente mayor de la sociedad es como una verdad decir que tenemos malos hábitos, como ser desordenados, que salimos mucho, etc." (Palazzo \& Marchese, 09 de octubre de 2013, texto 20).

Oposición "nosotros"/"ellos": "la sociedad con sus protocolos nos abruma" (Palazzo \& Marchese, 09 de octubre de 2013, texto 1), "Somos más parecidos a ellos de lo que piensan, solo que todavía no hemos vivido tanto" (texto 34).

Estrategias de autonomía: las imágenes de afiliación y autonomía son categorías propuestas en el marco de los estudios de cortesía sociocultural como superadoras de los tradicionales conceptos de imagen positiva e imagen negativa de Brown y Levinson (Bravo, 2002). La autonomía remite a todos los comportamientos relacionados con cómo una persona desea verse y ser vista por los demás como un individuo con contorno propio dentro del grupo. "Estoy en mi curso y 
escucho a mis compañeros hablar de qué van a 'hacer con su vida' y me preocupo cuando algunos dicen que ni siquiera saben qué cosas les gustan" (texto 34).

Estrategias de afiliación: comportamientos en los que se refleja cómo una persona desea verse y ser vista por los demás en cuanto a aquellas características que la identifican con el grupo. "[...] la gente adulta no entiende que estamos en otra época, con mucha más libertad de expresión" (Palazzo \& Marchese, 09 de octubre de 2013, texto 11), "Y esa lucha es la que los adultos no ven y sin intención alguna hacen nuestra lucha más dura" (texto 2 ).

\section{Estrategias discursivas locales de representación.}

Enumeración: "a diferencia de otros años, en nuestra 'niñez', pasamos cada etapa con paciencia, sin celulares, poco Internet, más estudio y nada de vicios como el alcohol, droga y cigarros" (Palazzo \& Marchese, 09 de octubre de 2013, texto 9).

Narración: "recuerdo haber sido niño y desvelarme pensando qué se sentiría ser adolescente, expectante y aterrado por crecer" (Palazzo \& Marchese, 09 de octubre de 2013, texto 32 ).

Descripción de acciones: "abro los ojos con la intención de despertarme, lucho para lograr superar mi cama después de no dormir el tiempo necesario. Me lavo la cara, me visto y lavo los platos que anoche sucios dejé en la mesada. Desayuno a medias [...]" (Palazzo \& Marchese, 09 de octubre de 2013, texto 3).

Preguntas retóricas: “ ¿acaso no existen jóvenes responsables?" (Palazzo \& Marchese, 09 de octubre de 2013, texto 7), "¿Alguna vez se preguntaron a qué se debe esta rebeldía?", “¿La juventud está realmente perdida o tan solo un porcentaje de ellos?”, “Soy lo que quiero ser?" (texto 2).

\section{Conclusiones}

Ningún enunciado está vacío de ideología y de referencia a algún discurso dominante que impone los valores aceptados de los signos ideológicos, ya que en cada acto enunciativo se ratifica o ratifican ese/esos discursos como materialización de la conciencia (Raiter, 2003, p. 175).

Las distintas informaciones y opiniones acerca de los jóvenes tienen significado ideológico (Van Dijk, 2003), pues responden a las preguntas sobre identidad, prácticas, objetivos, valores y sobre su relación con otros grupos. El análisis del instrumento seleccionado nos permite establecer una serie de consideraciones respecto de los modos de visibilidad de la problemática juvenil desde la experiencia de escritura en el aula, y teniendo en cuenta que todo discurso es opaco. Por tanto, requiere de la tarea del investigador para desentrañar los aspectos de la cognición social que lo atraviesan y dan sentido:

1. La juventud, como concepto en la memoria social, es una construcción discursiva, estructurada sobre representaciones históricas, provenientes de los discursos adultocéntricos, institucionales y comunicacionales.

2. Las representaciones más recurrentes puestas en discurso son las de: la juventud está perdida, la juventud es el futuro. Responden a un discurso dominante conformado por los elementos de esas representaciones: moratoria social, descontrol, anomia. Los discursos de los estudiantes parten de esas premisas, en un sentido dialógico, para enunciar sus puntos de vista como modo de respuesta. el ensayo.

3. El género discursivo que prevalece es

4. Las categorías de representación en los enunciados muestran pertenencia grupal como generación; se habla desde una edad social con 
nostalgia de la niñez o en preparación para ser adulto, o bien en oposición con los modos de ser y los discursos adultos. Sin embargo, prima el discurso de la normalidad, el control. En este sentido, operan las estrategias de afiliación (ser visto como individuos dentro de un grupo social que no responde a las representaciones negativas) y de autonomía (mostrarse como sujeto con identidad propia dentro de un grupo).

5. Las instancias de enunciación oscilan entre la primera persona, el "nosotros" generacional y la tercera persona que modaliza asertivamente los enunciados.

6. El concepto de "verdad" se asocia con el de "realidad" o evidencia. Así, las "verdades" se enuncian desde el lugar de joven, mientras que las "mentiras" o falsedades, o las visiones reductoras de la realidad provienen de los adultos y los medios masivos de comunicación, internalizados como agentes sociales de consolidación de un prototipo juvenil determinado.

7. Las creencias sociales que operan son las $s$ y las $p s$.

8. La juventud, su juventud, se delinea con rasgos contradictorios: es (en el habitus, usos y modos de estar juntos) una etapa de disfrute y libertad, enmarcada en un contexto de complacencia al mandato adulto. Es posibilidad de ser presente con obligación de proyectarse al futuro. Entre estos extremos, se enuncian las variables de clase (no se menciona el género en ningún caso) y territorio como condicionantes que impiden tanto ser el presente como imaginarse el futuro.

El análisis de este corpus acotado debe comprenderse a la luz de un proceso más complejo, donde se interpela a los estudiantes de secundaria como sujetos sociales, miembros de grupos, pero también individuos con capacidad para hacer visible sus subjetividades, ponerlas en discurso, hacer lecturas críticas de la realidad interactuando con la vida cotidiana y con discursos académicos.

El camino es arduo, ya que existen estructuras rígidas que banalizan o silencian esta forma de práctica discursiva a lo largo de décadas de institucionalización del conocimiento. Así mismo, las problemáticas juveniles en el contexto de los estudios de juventudes, no forman parte del currículo docente, hecho que puede revertirse paulatinamente con este tipo de prácticas pedagógicas.

En el transcurso de esta experiencia se destacó la importancia de repensar y transformar determinados modelos de enseñanzaaprendizaje que subyacen anquilosados en la escuela secundaria. Por ejemplo, la práctica comunicativa más frecuente de transmisión y demostración del saber en la institución escolar es la de evaluaciones escritas e individuales de recuperación de información textual; clases expositivas monológicas, tanto por parte de docentes como de alumnos; monografías; etc.

Así se fortalecen aspectos de una identidad lingüística vinculada a la mera recepción o repetición y no tanto a la creatividad, a desentrañar discursos hegemónicos, a cuestionar lo dado. Este panorama posibilita la apertura de acciones y prácticas que privilegien la autoría de la palabra pensamiento en la transmisión, la recepción crítica y la producción del conocimiento.

\section{Notas}

${ }^{1}$ Esta categorización se analizó en otras prácticas discursivas en torno a los jóvenes, en relación con la participación política y la construcción discursiva en la prensa escrita local y nacional (Palazzo, 2012; 2013).

${ }^{2}$ Citaremos ejemplos concretos de los enunciados que resultan representativos, mencionando el número de orden en el que los organizamos, del 1 al 34. No se incluyen los textos 
completos, ya que excederían ampliamente el número de páginas permitidas para la publicación de este artículo.

${ }^{3}$ Tomamos este concepto en el sentido sociológico de papel o función que cumplen en la sociedad las personas. Lo diferenciamos del de "edad biológica" y de "edad psicológica" (competencia conductual) (Palazzo, 2013). De acuerdo con Villa y Rivadeneira (1999) las distintas edades sociales (niñez, juventud, adultez, vejez) varían históricamente, están definidas por ciertas legitimidades y formas de actuar, y reflejan los efectos de las normas que rigen los comportamientos de los individuos.

\section{Referencias}

Bajtín, M. (1982). Estética de la creación verbal. México: Siglo XXI Editores.

Bravo, D. (Ed.) (2002). Actividades de cortesía, imagen social y contextos socioculturales: una introducción. En Actas del Primer Coloquio Edice (pp. 98-108). Estocolmo: Universidad de Estocolmo. Recuperado de http:www.primercoloquio.edice.org/ Actas/actas.htm

Haidar, J.(1992). Las materialidades discursivas: un problema interdisciplinario. Alfa, 36, 139-147. Recuperado de http://seer.fclar. unesp.br/alfa/article/viewFile/3914/3595

Montecino-Soto, L. A. (2005). Cortesía, ideología y representaciones discursivas en la gestión conversacional de jóvenes chilenos. Onomázein, 2(12), 9-22. Recuperado de http://www.redalyc.org/ articulo.oa? $\mathrm{id}=134516558001$

Palazzo, M. G. (2012). Juventud, ideología y discurso. En A. Zaffaroni (Coord.), Estudios sobre juventudes en Argentina II. Lineas prioritarias de investigación en el área jóvenes/juventud: la importancia del conocimiento situado (pp. 85-101).
Salta: EUNSa-ReIJA. Recuperado de http://www.unsa.edu.ar/biblio/reija2/

libro_reija_12.pdf

Palazzo, M. G. (2013). Discursos y representaciones sobre la juventud en la prensa: entre el futuro y la perdición. Revista del Instituto de Investigaciones Lingüisticas y Literarias Hispanoamericanas/Nueva época (RILL), Significación y Comunicación. Experiencias lingüisticas en Hispanoamérica, 18(1), 51-69. Recuperado de http://insil.com.ar/adminis/up-load/ upload/RILL-2013.pdf

Palazzo M. G., \& Marchese, R. (09 de octubre de 2013). Verdades y mentiras sobre nosotros (Material de archivo elaborado en el marco del Proyecto "Prácticas discursivas en diversos contextos presentes y pasados: Ele, ciberespacio, medios de comunicación y otros”). Argentina: Universidad Nacional de Tucumán.

Pardo-Abril, N. (2003). Análisis Crítico del Discurso y representaciones sociales: un acercamiento a la comprensión de lectura. En Berardi, L (Ed.), Análisis Críticodel Discurso, perspectivas latinoamericanas. Santiago: Frasis Editores.

Peralta, D. (2005). El Periodismo según La Razón a fines de la etapa Cortejanera: 19171921. Buenos Aires: Universidad Nacional de General Sarmiento. Recuperado de http://www.ungs.edu.ar/cm/uploaded_files /publicaciones/151_ii21.pdf

Raiter, A. (2003). Lenguaje y sentido común. Las bases para la formación del discurso dominante. Buenos Aires: Biblos.

Requejo, I. (2002). Autorías de la palabra y del pensamiento: el habla institucional(izada). La Revista, Órgano de Difusión del Departamento de Extensión, Facultad de Filosofia y Letras UNT, 4, 19-24. 
Requejo, I. (2004). Lingüistica Social y autorías de la palabra y del pensamiento: temas de debate en Psicología Social y Educación. Buenos Aires, Ediciones Cinco.

Remedi, G. (2004). Representaciones de la ciudad: apuntes para una crítica cultural (I). Recuperado de: http://www.henciclopedia.org.uy/autores/Remedi/Ciudad1.htm

Sarlo, B. (30 de junio de 2006). ¿Quién perdió a la juventud perdida?. Clarin.com. Recuperado de http://edant.clarin.com/diario/2006/07/30/sociedad/s-01242816.htm

Urresti, M. (1999). Cambio de escenarios sociales, experiencia juvenil urbana $\mathrm{y}$ escuela. En E. Tenti (Comp.), Una escuela para los adolescentes (pp. 9-72). Buenos Aires: UNESCO; UNICEF. Recuperado de http://unesdoc.unesco.org/ images/0011/001185/118515so.pdf

Van Dijk, T. (2003). Ideología y discurso. Barcelona: Ariel.

Villa, M., \& Rivadeneira, L. (2001). El proceso de envejecimiento de la población en América Latina y el Caribe: una expresión de la transición demográfica. Encuentro Latinoamericano y Caribeño sobre las personas de Edad, ponencias presentadas al seminario técnico "Cepal". Santiago de Chile. 
